\title{
Synthesis of Quadrangularin A and Pallidol
}<smiles>COc1ccc(C(O)c2c(/C=C/c3cc(OC)cc(OC)c3)cc(OC)cc2OC)cc1</smiles>

A<smiles>COc1cc(/C=C/c2cc(OC)cc(OC)c2C2CCCCCC2)cc(OC)c1</smiles>

C
Synthesis of Natural

Products and

Potential Drugs

\section{Key words}

cationic cyclization

Ramberg-Bäcklund reaction

Friedel-Crafts alkylation

SYNFACTrenth

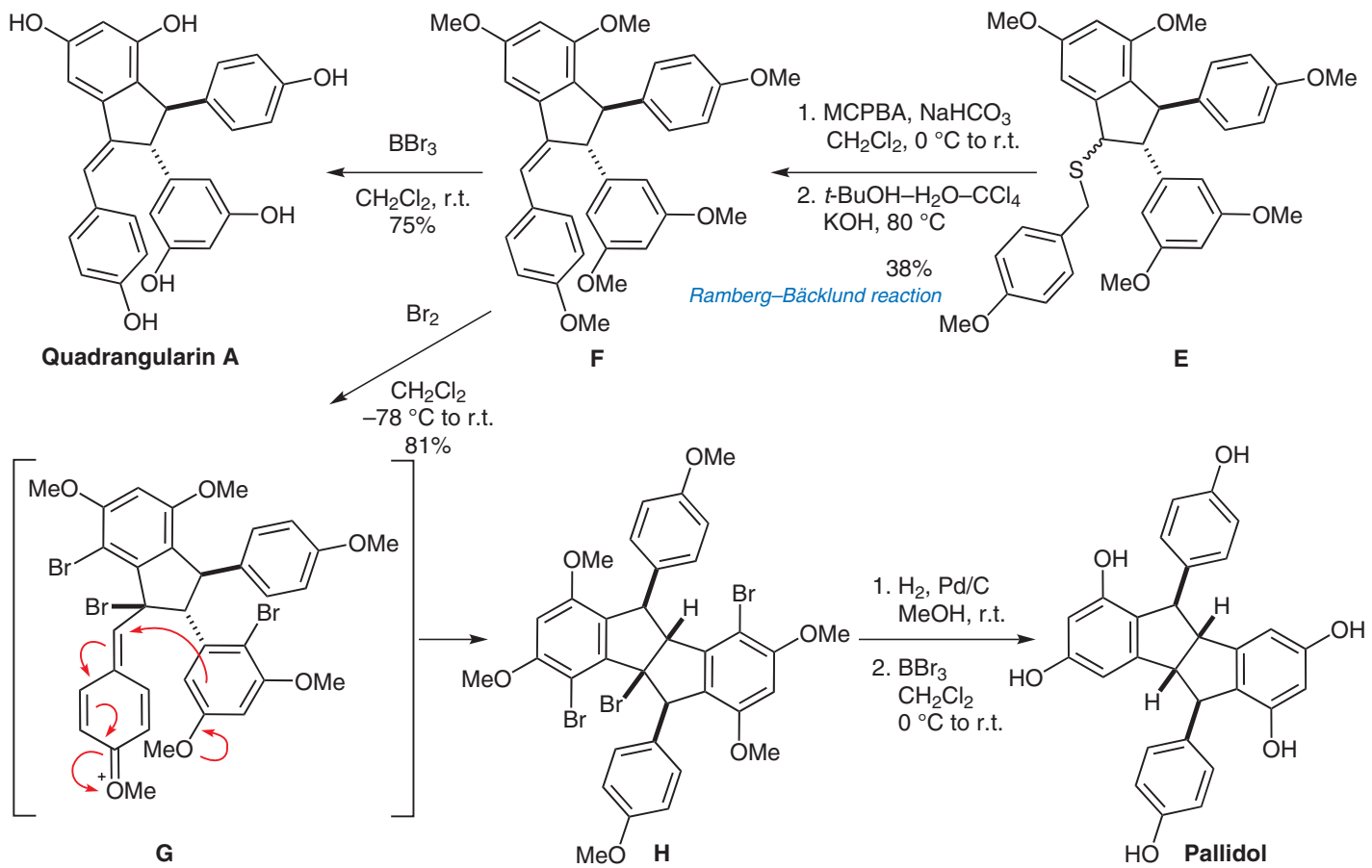

Significance: Resveratrol-based oligomers are produced combinatorially by plants in response to environmental stress. Snyder and co-workers report that the core structure $\mathbf{A}$ can be transformed to every member of the family by simply altering reagents and reaction conditions. Pallidol, quadrangularin, ampelopsins D and F, paucifloral F, and hemsleyanol $E$ were all synthesized by related cationic cyclization cascades.
Comment: Treatment of $\mathbf{A}$ with acid generated carbocation $\mathbf{C}$ that cyclized regioselectively followed by cation capture by thiol B. The resultant thioether $\mathbf{E}$ was used in a Ramberg-Bäcklund rearrangement to install the fourth aromatic ring of F, the precursor to quadrangularin A. A further cationic cyclization of $\mathbf{F}$ generated the tetracyclic array of $\mathbf{H}$, a precursor to pallidol. 